Check for updates

Cite this: RSC Adv., 2018, 8, 19512

\title{
Conjugated polymer-based carbonaceous films as binder-free carbon electrodes in supercapacitors $\uparrow$
}

\author{
Satoshi Matsushita, (DD *a Bairu Yan, (D) ${ }^{\text {b }}$ Takanori Matsui, ${ }^{\text {b }}$ Je-Deok Kim (D) ac \\ and Kazuo Akagi (iD ${ }^{b}$
}

We present a facile preparation method for carbonaceous film electrodes using poly(3,4ethylenedioxythiophene) (PEDOT) and polyacetylene (PA) films as precursors via a morphology-retaining carbonization process. Carbonization was performed on acceptor-doped conjugated polymer films in the temperature range of $600-1100{ }^{\circ} \mathrm{C}$. The obtained carbonaceous films had similar surface morphologies to those of the original conjugated polymer films. The carbonaceous film prepared from the electrochemically synthesized PEDOT film and the carbon film prepared from the chemically synthesized PA film showed hierarchical porous structures consisting of granular and fibril morphologies, respectively. The PEDOT and PA films carbonized at $1100{ }^{\circ} \mathrm{C}$ exhibited average electrical conductivities of $2.1 \times 10^{0} \mathrm{~S} \mathrm{~cm}^{-1}$ and $9.9 \times 10^{1} \mathrm{~S} \mathrm{~cm}^{-1}$, respectively. The carbonaceous films could be used as binder-free carbon electrodes in supercapacitors, and the PEDOT-based carbonaceous film prepared in the range of $1000-1100{ }^{\circ} \mathrm{C}$ exhibited the most efficient performance on the basis of the electrochemical capacitance in neutral and alkaline aqueous solutions determined from cyclic voltammograms and galvanostatic charge/discharge curves. This approach requires no binders/additives and no further activation processes or additional treatments for the enhancement of the capacities of the carbon materials, enabling one-step fabrication and their direct use as carbon electrodes for energy-storage devices. This is the first report of PEDOT- and PA-based carbonaceous films being used as carbon electrodes in supercapacitors.

Received 10th January 2018

Accepted 18th May 2018

DOI: $10.1039 / c 8 \mathrm{ra00267c}$

rsc.li/rsc-advances

\section{Introduction}

Electrical energy-storage devices, such as rechargeable batteries and supercapacitors, are readily applicable in portable consumer electronics, electric transportation technology, electric power industry, and so on. In recent years, society has demanded lightweight and space-saving electrical energystorage devices with high charging capacities towards further miniaturization of electric devices. In particular, supercapacitors are a relatively new type of energy-storage device, which lie between conventional capacitors and secondary batteries, due to their fundamental advantages, such as a high power densities, fast charge/discharge rates, and long cycle lifetimes. ${ }^{1-8}$ Unlike lithium-ion batteries, which operate via

\footnotetext{
${ }^{a}$ Polymer Electrolyte Fuel Cell Group, Global Research Center for Environmental and Energy Based on Nanomaterials Science (GREEN), National Institute for Materials Science (NIMS), 1-1 Namiki, Tsukuba, Ibaraki 305-0044, Japan. E-mail: MATSUSHITA.Satoshi@nims.go.jp

${ }^{b}$ Department of Polymer Chemistry, Kyoto University, Katsura, Kyoto 615-8510, Japan ${ }^{\prime}$ Hydrogen Production Materials Group, Center for Green Research on Energy and Environmental Materials, NIMS, 1-1 Namiki, Tsukuba, Ibaraki 305-0044, Japan $\dagger$ Electronic supplementary information (ESI) available: Materials and measurements, EDOT and acetylene polymerizations, Scheme S1, Fig. S1-S30, and Tables S1-S3. See DOI: 10.1039/c8ra00267c
}

charge/discharge processes with a slow electrochemical reaction, the charge/discharge in supercapacitors occurs via a fast process, such as ion adsorption/desorption (electric doublelayer capacitance: EDLC) and fast redox reactions (pseudocapacitance). Currently, activated carbon materials are widely used as an electrode material for practical applications in supercapacitors because they have porous structures, high specific surface areas, and electrochemical stabilities, which are indispensable factors for exhibiting high performance in electric devices. However, activated carbon powders must be fabricated into films on a current collector by mixing with binders and conducting agents, such as carbon black, for use as carbon electrode materials in supercapacitors. Therefore, an easier one-step approach for producing a carbon electrode material is desired for the development of advanced supercapacitors. To this end, a good approach is to use a carbon-based film as a supercapacitor electrode.

Various freestanding carbon-based films for supercapacitor electrode materials have been prepared by using a variety of synthetic approaches with carbon nanotubes (CNTs), ${ }^{9}$ graphene-based materials, ${ }^{10}$ carbon fibers, ${ }^{11}$ amorphous carbons, ${ }^{12}$ etc. Although these binder-free carbon electrodes show excellent capacitive performances with distinct cycling capabilities, it is inherently difficult to control the structures 
and morphologies of carbon materials, limiting the structural variety of the carbon electrodes. Indeed, there have only been a few reports on freestanding carbon-based films with controlled morphologies that are directly usable as supercapacitor electrodes without needing a time-consuming filmmaking process on a current collector. If it is possible to synthesize carbonization precursor polymer films with hierarchical porous morphologies and the controlled morphologies are retained even after heat treatment, the obtained carbonbased films would be promising candidates for use as supercapacitor electrodes and would expand the morphological variety that polymeric materials have.

We have recently prepared a variety of morphologycontrolled carbonaceous and graphitic films from various conjugated polymers, such as polythiophene derivatives, ${ }^{13}$ polyacetylenes (PAs), ${ }^{14-17}$ and polyphenylene derivatives. ${ }^{18}$ In particular, freestanding carbonaceous films have been prepared from poly(3,4-ethylenedioxythiophene) (PEDOT) and PA films that have been synthesized through electrochemical and interfacial chemical polymerization methods in an isotropic solvent, respectively. ${ }^{13-16}$ The PEDOT film with hierarchical porous morphology can be directly obtained via the oxidative polymerization of EDOT as a monomer on an anode surface. In contrast, the interfacial polymerization method affords a PA film with a random fibril morphology. In a recent study, we have shown that a freestanding carbon film with its precursor morphology can be prepared from a fully doped PA film with iodine. ${ }^{\mathbf{1 4 - 1 6}}$ Furthermore, hierarchical helical carbonaceous and graphitic films with fibrous structures have been prepared from both conjugated polymers. Although the morphologycontrolled carbonaceous and graphitic films show good electrical and mechanical properties, practical applications based on their morphological functions have not yet been achieved. The conjugated polymer-based carbonaceous films are thought to be applicable as carbon electrodes for energy-storage devices composed of supercapacitors because of their electrochemical stabilities, high electrical conductivities, and good mechanical properties. Among the carbonaceous films, the PEDOT- and PAbased freestanding carbonaceous films are highly suitable candidates for the above-mentioned application. Recently, porous carbonaceous materials with high specific surface areas and superior capacitive behaviors, which have been prepared from various conjugated polymer-based frameworks, such as polyanilines, ${ }^{19}$ PEDOT ${ }^{20}$ conjugated microporous polymers, ${ }^{21}$ conjugated polymer networks, ${ }^{22}$ and porous aromatic frameworks $^{23}$ serving as carbonization precursors, have been achieved. However, since these carbonaceous materials are obtained as powders, all of them require binders for the fabrication of supercapacitor electrodes.

Here we present carbonaceous films prepared from conjugated polymer films as a new class of carbon electrodes in supercapacitors. First, we prepared freestanding carbonaceous films from PEDOT and PA films with hierarchical porous morphologies as potential carbonization precursors. Then we investigated the electrochemical properties of the carbonaceous films by focusing on specific capacitances determined by using cyclic voltammetry (CV) and galvanostatic charge/discharge (GCD) measurements.

\section{Results and discussion}

\subsection{Synthesis of PEDOT and PA films}

PEDOT films were synthesized via electrochemical polymerization in acetonitrile (ACN) using mono-EDOT as a monomer and tetra- $n$ butylammonium perchlorate (TBAP) as a supporting electrolyte. On the other hand, the PA film was synthesized by using interfacial acetylene polymerization in toluene with a Ziegler-Natta catalyst, tetra- $n$-butoxytitanium $\left[\mathrm{Ti}(\mathrm{O}-n-\mathrm{Bu})_{4}\right]$ and triethylaluminum $\left(\mathrm{Et}_{3} \mathrm{Al}\right)$. The full experimental details of the polymerization procedure are described in the ESI. $\uparrow$ The electrochemically produced PEDOT films are usually obtained in a doped state. We have recently discussed that the degree of crystallinity of the graphitic film prepared from a perchlorate ion $\left(\mathrm{ClO}_{4}{ }^{-}\right)$-doped PEDOT film up to $2600{ }^{\circ} \mathrm{C}$ is higher than that prepared from an undoped PEDOT film. ${ }^{13}$ Since a highly crystalline carbon film usually has high electrical conductivity, the $\mathrm{ClO}_{4}{ }^{-}$-doped PEDOT film was used as a carbonization precursor polymer film in the present study. The amount of doped $\mathrm{ClO}_{4}{ }^{-}$in the PEDOT film was determined by using elemental analysis: $\mathrm{C}, 40.38 ; \mathrm{H}, 2.75 ; \mathrm{S}, 18.06$; and $\mathrm{Cl}, 5.53$. The ratio of doped $\mathrm{ClO}_{4}{ }^{-}$to EDOT unit in the PEDOT film $\left(\mathrm{ClO}_{4}{ }^{-}\right.$EDOT) was calculated to be $\left[\mathrm{EDOT}\left(\mathrm{ClO}_{4}{ }^{-}\right)_{0.28}\left(\mathrm{H}_{2} \mathrm{O}\right)_{0.43}\right]_{n}$ from the results of elemental analysis.

\subsection{Morphologies of PEDOT and PA films}

Freestanding PEDOT and PA films were obtained by polymerizing EDOT and acetylene, respectively. The inset in Fig. 1a is a photograph of the solution side of the PEDOT film with a dark blue color. The solution side of the PEDOT film and the gas side of the PA film exhibited a dull metallic luster. In contrast, the glass sides of the PEDOT and PA films exhibited a shiny metallic luster. Fig. 1a and b are scanning electron microscopy (SEM) images of the PEDOT film. The surface of the solution side of the PEDOT film exhibited a porous structure and a granular morphology in SEM images. In contrast, the glass side of the PEDOT film exhibited a wrinkled structure and a dense morphology compared with the solution side of the film (Fig. S2 in the ESI $\dagger$ ). Fig. 1c and d are SEM images of the PA film. The surface of the gas side of the PA film had a porous morphology consisting of entangled fibrils with a subnanometer scale diameter. On the other hand, the glass side of the PA film had a densely packed structure and randomly arranged fibril morphology (Fig. S3 in the ESI $\dagger$ ). The bulk density $\left(d_{\text {bulk }}\right)$ of the PA film is higher than that of the PEDOT film.

\subsection{TG-DTA curve for the PEDOT and PA films}

The thermal behaviors of acceptor-doped PEDOT and PA films in a heating run were investigated using thermogravimetricdifferential thermal analysis (TG-DTA) up to $1000{ }^{\circ} \mathrm{C}$ with a heating rate of $10{ }^{\circ} \mathrm{C} \mathrm{min}^{-1}$ under flowing nitrogen or oxygen gas. In thermogravimetric analysis (TGA) measurements, the $\mathrm{ClO}_{4}{ }^{-}$-doped PEDOT film was stable up to $202{ }^{\circ} \mathrm{C}$, and the major decomposition of the film occurred in the region between 202 

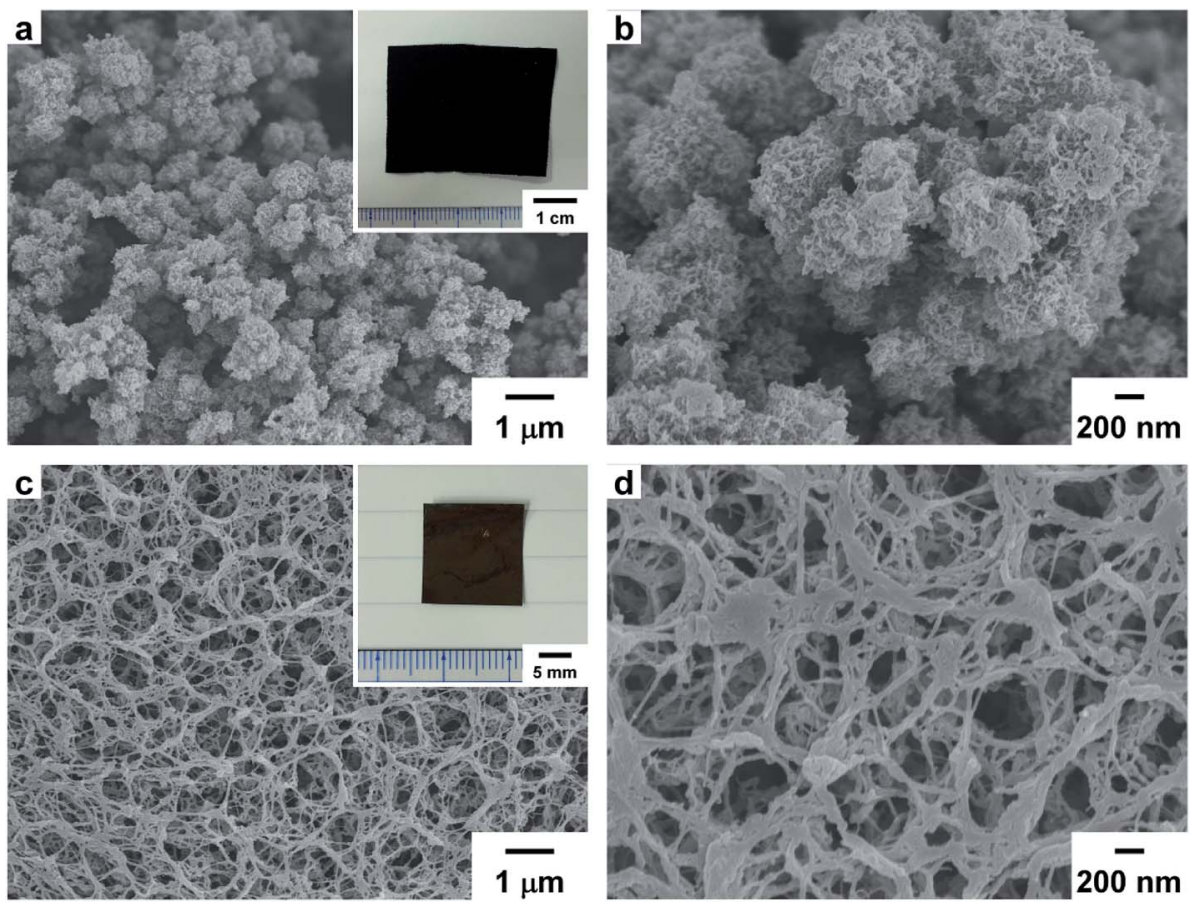

Fig. 1 ( $a$ and b) SEM images of the solution side of the PEDOT film. The inset shows a photograph of the solution side of the PEDOT film [thickness $(t)=163 \pm 31 \mu \mathrm{m}, d_{\text {bulk }}=0.52 \mathrm{~g} \mathrm{~cm}^{-3}$, electrical conductivity $(\sigma)=16 \pm 6 \mathrm{~S} \mathrm{~cm}^{-1}$ ]. (c and d) SEM images of the gas side of the PA film. The inset shows a photograph of the gas side of the PA film $\left(w \times l=15 \times 15 \mathrm{~mm}, t=99 \pm 1 \mu \mathrm{m}, d_{\mathrm{bulk}}=0.72 \mathrm{~g} \mathrm{~cm} \mathrm{~cm}^{-3}\right)$.

and $388^{\circ} \mathrm{C}$ (Fig. 2a). Continuous decomposition was observed in the region between 388 and $1000{ }^{\circ} \mathrm{C}$ after the major decomposition..$^{24}$ The initial weight decrease $\left(<100^{\circ} \mathrm{C}\right)$ in the TG curve was attributed to evaporation of adsorbed moisture from the film. In the DTA curve of an iodine-doped PA film, an exothermic peak attributed to a cis-trans isomerization was observed at $129{ }^{\circ} \mathrm{C}$. The weight of the PA film radically decreased with an increase in temperature up to $194{ }^{\circ} \mathrm{C}$ due to evaporation of the excess adsorbed iodine, as seen in the TG curve. A small decrease in weight was then observed in the range of $451-672{ }^{\circ} \mathrm{C}$. In the DTA curve of the iodine-doped PA film, no clear endothermic peaks attributed to thermal decomposition were observed (Fig. 2b). The main purpose of iodine-doping in this study was to prevent thermal decomposition of the PA film during heat treatment and to produce a freestanding carbon film which has the precursor morphology reported previously. ${ }^{14-16}$ A TG-DTA curve for a pristine PA film $\left([\mathrm{CH}]_{n}\right)$ is shown in Fig. S5b (ESI $\dagger$ ).

\subsection{Carbonization of PEDOT and PA films}

The PEDOT film was carbonized in the temperature range of 600-1100 ${ }^{\circ} \mathrm{C}$ using an electric furnace in flowing argon or nitrogen gas. The carbonization time and the heating rate for the carbonaceous films prepared in the temperature range of $600-1000{ }^{\circ} \mathrm{C}$ were $60 \mathrm{~min}$ and $10^{\circ} \mathrm{C} \mathrm{min}{ }^{-1}$, respectively. For the a

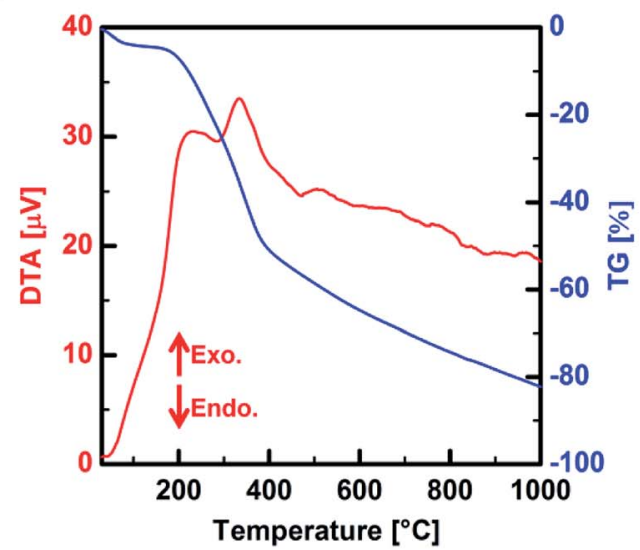

b

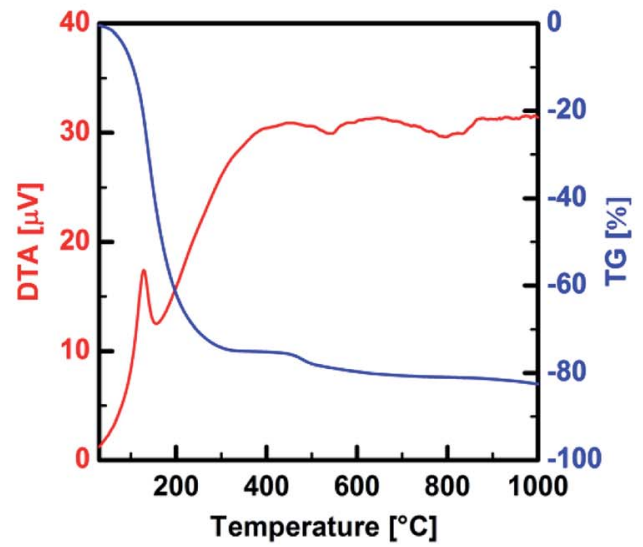

Fig. 2 TG-DTA curves for the precursor polymer films obtained under nitrogen gas. (a) $\mathrm{ClO}_{4}{ }^{-}$-doped PEDOT film and (b) iodine-doped PA film $\left(\left[\mathrm{CHI} \mathrm{O}_{0.34}\right]_{n}\right)$. 
carbonaceous film prepared at $1100{ }^{\circ} \mathrm{C}$, the PEDOT film was first carbonized at $600{ }^{\circ} \mathrm{C}$ for $30 \mathrm{~min}$, and then the carbonized film was subjected to a second thermal treatment at $1100{ }^{\circ} \mathrm{C}$ for $30 \mathrm{~min}$ at a heating rate of $5{ }^{\circ} \mathrm{C} \mathrm{min}^{-1}$. The two-step heattreatment procedure is hereafter called "1100 ${ }^{\circ} \mathrm{C}$ ". Freestanding carbonaceous films with thicknesses in the range of 64-144 $\mu \mathrm{m}$ were obtained from the PEDOT film by carbonizing in the range of $600-1100{ }^{\circ} \mathrm{C}$ (Fig. 3a, inset). The $d_{\text {bulk }}$ values of the carbonaceous films were lower than that of the precursor PEDOT film and decreased with an increase in the heattreatment temperature (Fig. S7 in the ESI $\dagger$ ). The hydrogen content of the PEDOT film carbonized at $1100{ }^{\circ} \mathrm{C}$ was lower than that of the film carbonized at $600{ }^{\circ} \mathrm{C}$. It is worth noting that the carbonized films still include sulfur atoms even at $1100{ }^{\circ} \mathrm{C}$. The sulfur content of the carbonized PEDOT film decreased with an increase in the heat-treatment temperature (Fig. S8a in the ESI $\dagger$ ). Thus, the amount of heteroatoms doping could be well controlled. In contrast, the carbon content of the carbonized PEDOT film increased with an increase in the heat-treatment temperature. We have recently performed X-ray photoelectron spectroscopy (XPS) on a PEDOT-based carbon film prepared at $800{ }^{\circ} \mathrm{C}$ to investigate bonding states of the sulfur atom in the carbon film. ${ }^{13 a}$ From the XPS profile, the sulfur atoms are mainly found in thiophene-like structures in the present carbonaceous films. It is well-known that the electrochemical properties of carbon materials can be improved by doping them with heteroatom species, such as nitrogen, oxygen, phosphorus, boron, and sulfur. Among heteroatom-doped carbon materials, there are some examples of sulfur-doped carbon materials being used in supercapacitors. ${ }^{25}$ It has been reported that the doped carbon materials show a capacitance superior to that of undoped carbon materials. In addition, from energy dispersive X-ray spectrometry (EDS) analysis, the PEDOT-based carbonaceous film contained both oxygen and sulfur species (Fig. S9 in the ESI $\dagger$ ).

The PA film was carbonized in the range of $600-1100{ }^{\circ} \mathrm{C}$ using a method similar to the carbonization of the PEDOT film. Iodine-doping was performed before the carbonization process by exposing the film to iodine gas at room temperature for $20-$
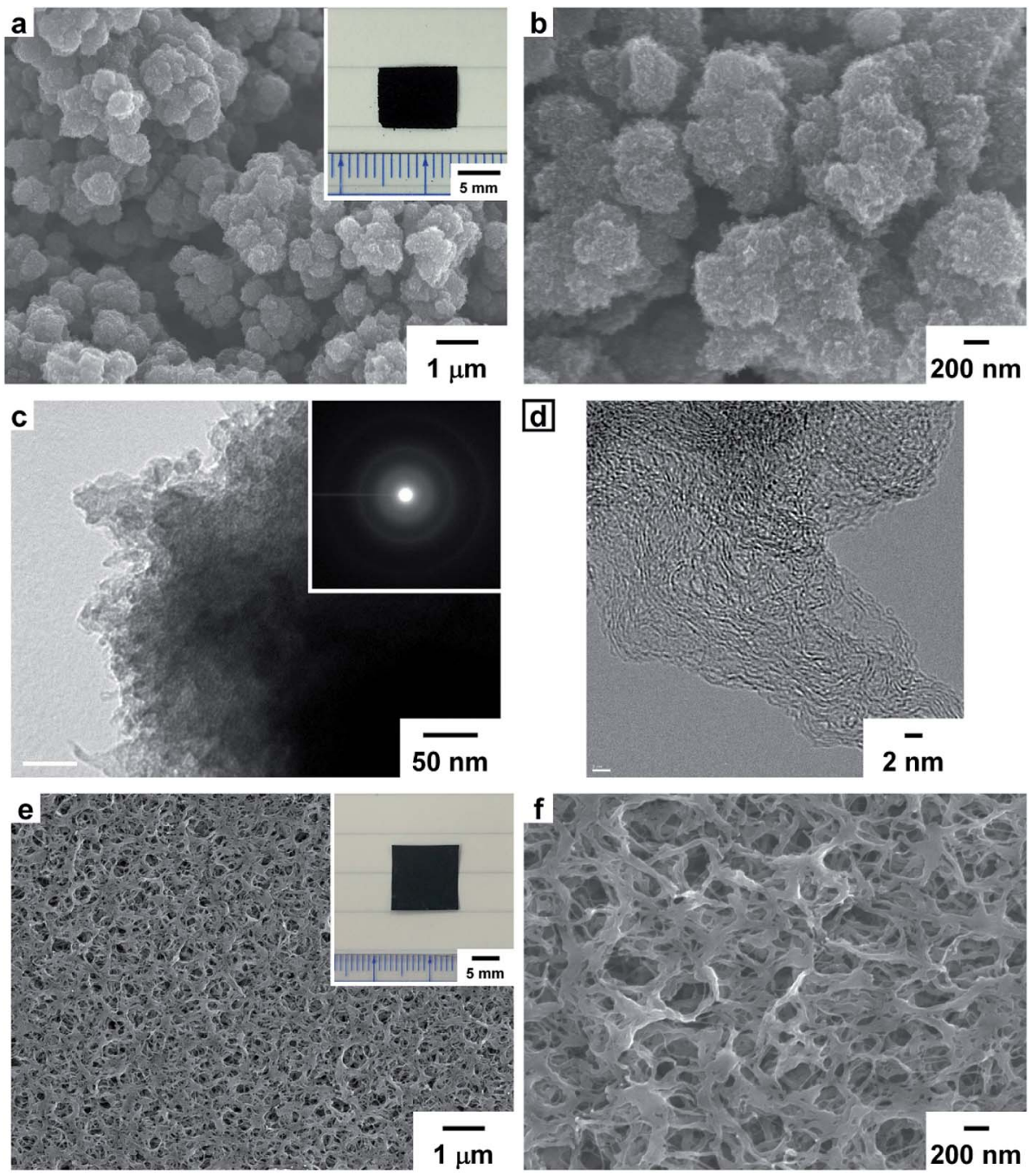

Fig. 3 ( $a$ and b) SEM images of the solution side of the PEDOT film carbonized at $1100{ }^{\circ} \mathrm{C}$. The inset shows a photograph of the solution side of the carbonaceous film $\left(w \times l=7.0 \times 9.0 \mathrm{~mm}, t=87 \pm 10 \mu \mathrm{m}, d_{\text {bulk }}=0.27 \mathrm{~g} \mathrm{~cm}^{-3}, \sigma=2.1 \pm 0.3 \mathrm{~S} \mathrm{~cm}^{-1}\right)$. (c and d) TEM images of the carbonized PEDOT. Inset shows an SAED pattern of the carbonized PEDOT. (e and f) SEM images of the gas side of the PA film carbonized at $1100{ }^{\circ} \mathrm{C}$. The inset shows a photograph of the gas side of the carbon film $\left(w \times l=12 \times 12 \mathrm{~mm}, t=75 \pm 1 \mu \mathrm{m}, d_{\text {bulk }}=0.83 \mathrm{~g} \mathrm{~cm}^{-3}, \sigma=99 \pm 6 \mathrm{~S} \mathrm{~cm}{ }^{-1}\right)$. 
$28 \mathrm{~h}$ in a sample bottle. The amount of doped iodine in the films was determined by weighing the doped PA films. The atomic ratio of doped iodine to carbon in the PA film (I/C) was in the range of $0.17-0.32$. Freestanding carbon films with thicknesses in the range of 66-76 $\mu \mathrm{m}$ were obtained by the carbonization of the PA film in the range of $600-1100{ }^{\circ} \mathrm{C}$ (Fig. 3e, inset). The $d_{\text {bulk }}$ values of the carbon films were higher than that of the PA film (Fig. S7 in the ESI $\dagger$ ). On the basis of the results of elemental analysis, no iodine was detected in the carbon films prepared at temperatures higher than $800{ }^{\circ} \mathrm{C}$. Isotropic thermal shrinkage was observed in both polymer films during heat treatment. Carbonization yields, $d_{\text {bulk }}$ values, elemental analyses, and $\sigma$ values of the PEDOT, PA, and carbonaceous films are summarized in Table 1.

\subsection{Morphologies of the PEDOT- and PA-based carbonaceous films}

Fig. 3a and b show SEM images of the PEDOT-based carbonaceous film prepared at $1100{ }^{\circ} \mathrm{C}$. In the SEM images of the solution side of the carbonaceous film, fine particles similar to those of the PEDOT film were observed. Fig. 3c and $d$ show transmission electron microscopy (TEM) images of the PEDOTbased carbonaceous films. In the high-resolution TEM image, an amorphous structure in the carbonized PEDOT was observed. The amorphous carbon structure was further confirmed by using a selected-area electron-diffraction (SAED) pattern (Fig. 3c, inset), in which only diffused halos characteristic of a turbostratic carbon state were observed. Fig. 3e and $\mathrm{f}$ show SEM images of the gas side of the PA-based carbon film prepared at $1100{ }^{\circ} \mathrm{C}$. An entangled fibril morphology similar to the structure of the PA film was observed on the surface of the carbon film. The hierarchical porous surface morphology of the solution side of the PEDOT-based carbonaceous film and the gas side of the PA-based carbon film should effectively adsorb a large amount of ion species during electrochemical charge and discharge processes. SEM images of the solution, gas, and glass sides of the carbonaceous films prepared at 600, 800, and $1000{ }^{\circ} \mathrm{C}$ are shown in the ESI (Fig. S10-S17†).

\subsection{XRD patterns of the PEDOT, PA, and carbonaceous films}

Fig. 4a shows X-ray diffraction (XRD) patterns of the PEDOT film. In the pattern, a sharp (100) reflection was observed at 13.1 $\AA\left(6.7^{\circ}\right.$ in $\left.2 \theta\right)$, and (400) and (020) reflections were observed at $3.5 \AA\left(25.8^{\circ}\right.$ in $\left.2 \theta\right)$. Fig. $4 \mathrm{c}$ shows XRD patterns of the PA film. Sharp (110) and (200) reflections were observed at $3.8 \AA$ (23.2 ${ }^{\circ}$ in $2 \theta$ ), and small (210) and (002) reflections were observed at $2.9 \AA$ $\left(30.9^{\circ}\right.$ in $\left.2 \theta\right)$ and $2.2 \AA\left(41.0^{\circ}\right.$ in $\left.2 \theta\right)$, respectively. It is clear from the XRD patterns that the PA film has a highly crystalline region inside the fibril. ${ }^{26}$ On the other hand, in the patterns for the carbonaceous films prepared in the range of $600-1100{ }^{\circ} \mathrm{C}$, no clear peaks were observed regardless of the heat-treatment temperature and kinds of precursor polymers in agreement with previously reported results (Fig. $4 \mathrm{~b}$ and d). ${ }^{\mathbf{1 3 a}, 16}$ The carbon films prepared from the PA film had slightly better degrees of crystallinity than those of the carbonaceous films prepared from the PEDOT film.

\subsection{Raman scattering spectra of the PEDOT, PA, and carbonaceous films}

Fig. 5 shows Raman spectra of PEDOT-based carbonaceous and PA-based carbon films. The Raman spectra for the carbonaceous films prepared at $800{ }^{\circ} \mathrm{C}$ showed broad D- and G-bands in the ranges of 1333-1336 and 1532-1559 $\mathrm{cm}^{-1}$, respectively, which is in agreement with previous results. ${ }^{\mathbf{1 3 a}, \mathbf{1 6}}$ The D-bands for the carbonaceous films increased in intensity with an increase in the heat-treatment temperature in the range of 600$1100{ }^{\circ} \mathrm{C}$. Raman intensity ratios of the G- and D-bands $\left(I_{\mathrm{G}} / I_{\mathrm{D}}\right)$ and $L_{\mathrm{a}}$ values of the carbonaceous films are summarized in Table S1 (ESI $\dagger$ ). The $I_{\mathrm{G}} / I_{\mathrm{D}}$ and $L_{\mathrm{a}}$ values decreased with an increase in the heat-treatment temperature.

Table 1 Carbonization yields, $d_{\text {bulk }}$ values, elemental analyses, and $\sigma$ values of the PEDOT, PA, and carbonaceous films prepared at various temperatures

\begin{tabular}{|c|c|c|c|c|c|c|c|c|c|}
\hline Polymer & $\begin{array}{l}\text { Heat-treatment } \\
\text { temp. }\left({ }^{\circ} \mathrm{C}\right)\end{array}$ & Precursor & $\begin{array}{l}\text { Carbonization } \\
\text { yield }(\%)\end{array}$ & $d_{\text {bulk }}\left(\mathrm{g} \mathrm{cm}^{-3}\right)$ & C (wt\%) & $\mathrm{H}(\mathrm{wt} \%)$ & $\mathrm{S}(\mathrm{wt} \%)$ & $\mathrm{Cl}(\mathrm{wt} \%)$ & $\sigma\left(\mathrm{S} \mathrm{cm}^{-1}\right)$ \\
\hline \multirow[t]{4}{*}{ PEDOT } & $\operatorname{Raw}^{a}$ & {$\left[\mathrm{EDOT}\left(\mathrm{ClO}_{4}{ }^{-}\right)_{0.28}\right.$} & $-^{b}$ & 0.52 & 40.38 & 2.75 & 18.06 & 5.53 & $1.6 \times 10^{1}$ \\
\hline & 800 & & 26 & 0.36 & 78.43 & 0.35 & 13.96 & $-^{c}$ & $1.4 \times 10^{-1}$ \\
\hline & 1000 & & 13 & 0.34 & 91.25 & 0.22 & 5.34 & $-^{c}$ & $1.6 \times 10^{\circ}$ \\
\hline & $1100^{d}$ & & $\begin{array}{l}35-36\left(600^{\circ} \mathrm{C}\right), \\
19-20\left(1100^{\circ} \mathrm{C}\right)\end{array}$ & 0.27 & 95.03 & $<0.2$ & 2 & $-^{c}$ & $2.1 \times 10^{0}$ \\
\hline & 600 & {$\left[\mathrm{CHI}_{0.26-0.32}\right]_{n}$} & $73-74$ & 0.96 & 91.2 & 1.94 & $-^{b}$ & $-^{b}$ & $2.1 \times 10^{-3}$ \\
\hline & 800 & {$\left[\mathrm{CHI}_{0.27-0.31}\right]_{n}$} & $70-73$ & 1.13 & 93.13 & 0.67 & $-^{b}$ & $-^{b}$ & $3.8 \times 10^{1}$ \\
\hline & 1000 & {$\left[\mathrm{CHI}_{0.17-0.30}\right]_{n}$} & $57-66$ & 0.95 & 93.5 & 0.29 & $-^{b}$ & $-^{b}$ & $9.7 \times 10^{1}$ \\
\hline & $1100^{d}$ & {$\left[\mathrm{CHI}_{0.21-0.30}\right]_{n}$} & $70-73\left(600^{\circ} \mathrm{C}\right)$ & 0.83 & 93.07 & $<0.2$ & $-^{b}$ & $-^{b}$ & $9.9 \times 10^{1}$ \\
\hline
\end{tabular}

${ }^{a}$ An untreated precursor polymer film. ${ }^{b}$ Not applicable. ${ }^{c}$ Data not available. ${ }^{d}$ The carbon film was prepared through a carbonization of a precursor polymer film at $600{ }^{\circ} \mathrm{C}$ for $30 \mathrm{~min}$ and the carbonized film was further heat treated at $1100{ }^{\circ} \mathrm{C}$ for 30 min with a heating rate of $5{ }^{\circ} \mathrm{C}$ min ${ }^{-1}$. ${ }^{e}$ After iodine doping. 
a

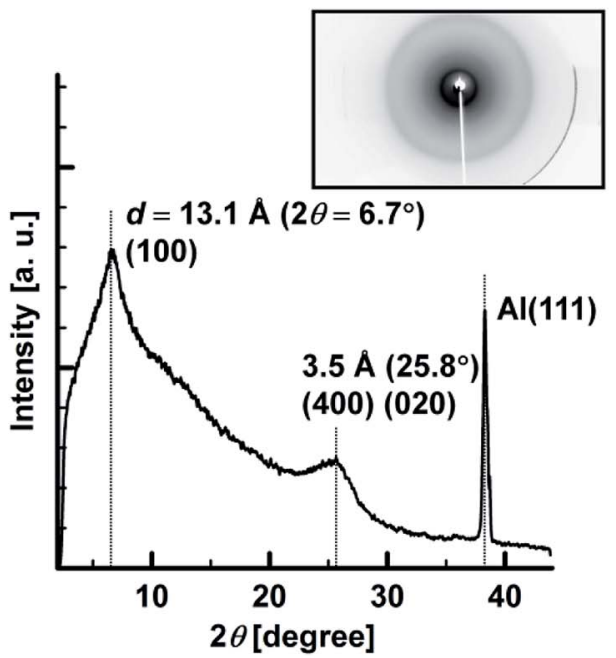

c.

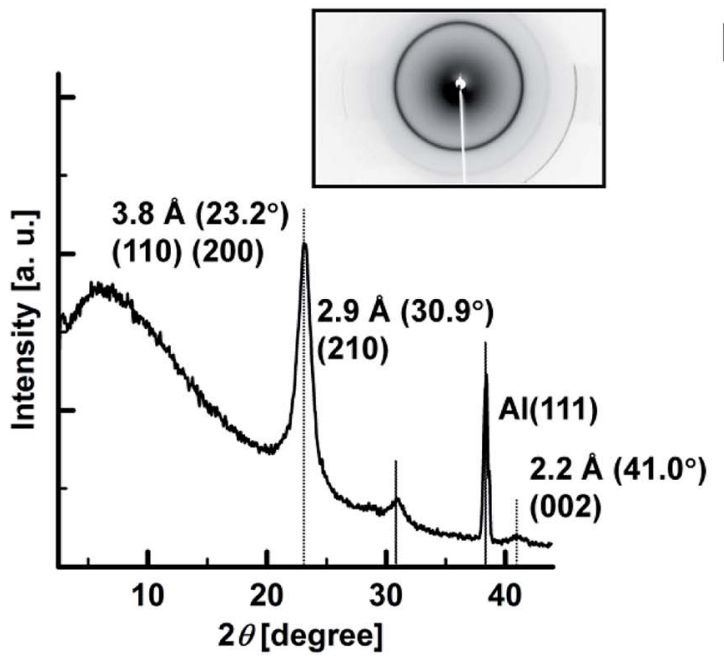

b

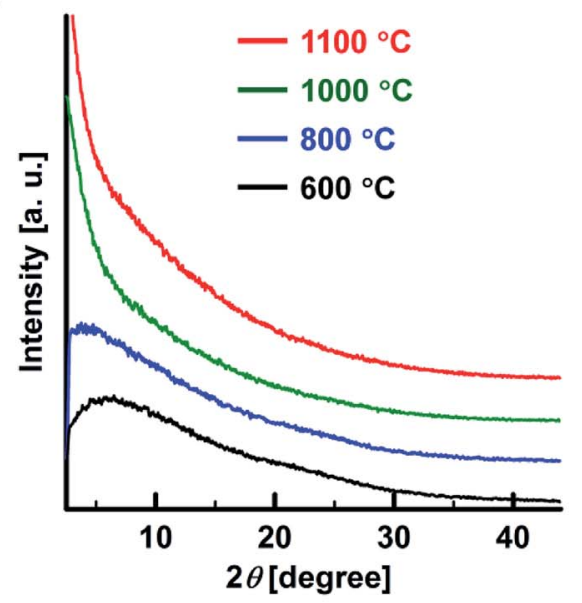

d

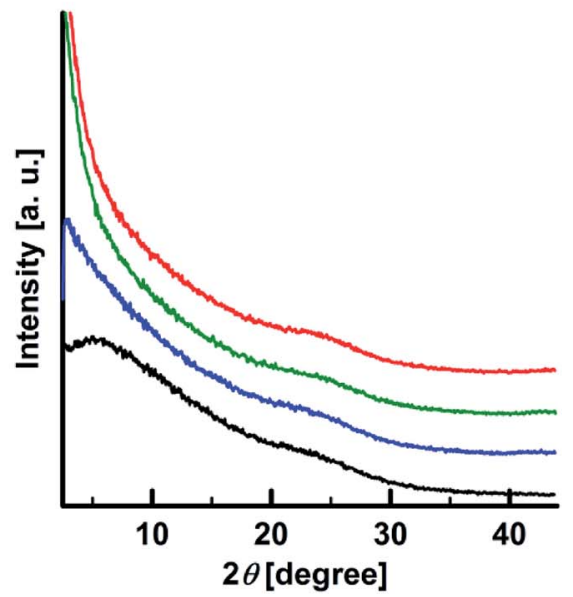

Fig. 4 XRD patterns of the (a) PEDOT, (b) PEDOT-based carbonaceous, (c) PA and (d) PA-based carbon films.

2.8 Surface areas, pore volumes, and pore sizes of the PEDOT- and PA-based carbonaceous films

Fig. S21 and S22 (ESI $\dagger$ ) show nitrogen adsorption/desorption isotherms and pore size distributions of the PEDOT-based carbonaceous films and PA-based carbon films prepared in the range of $1000-1100{ }^{\circ} \mathrm{C}$. The PEDOT-based carbonaceous film basically exhibited a type I adsorption isotherm characteristic of microporous materials. The Brunauer-Emmett-Teller (BET) specific surface area $\left(S_{\mathrm{BET}}\right)$ and micropore volume $\left(V_{\text {micro }}\right)$ of the carbonaceous film were in the ranges of $617-715 \mathrm{~m}^{2} \mathrm{~g}^{-1}$ and $0.22-0.26 \mathrm{~cm}^{3} \mathrm{~g}^{-1}$, respectively. The contents of the micropore surface area $\left(S_{\text {micro }} / S_{\text {BET }}\right)$ and volume $\left(V_{\text {micro }} / V_{\text {total }}\right)$ were determined to be $96 \%$ and in the range of $72 \%-85 \%$, respectively. In contrast, the PA-based carbon film had a much lower $S_{\mathrm{BET}}$ value than that of the PEDOT-based carbonaceous film. The $S_{\text {BET }}, S_{\text {micro }}, V_{\text {total }}, V_{\text {micro }}$, and average pore diameter $\left(D_{\text {average }}\right)$ values for the carbonized PEDOT are summarized in Table 2 .

\subsection{Electrical conductivities of the PEDOT, PA, and carbonaceous films}

Electrical conductivities of the PEDOT, PA, and carbonaceous films were measured using a four-point probe method at room temperature. The doped PEDOT film had a conductivity of $1.6 \times$ $10^{1} \mathrm{~S} \mathrm{~cm}^{-1}$. The PA film with doped iodine $\left(\left[\mathrm{CHI}_{0.31}\right]_{n}\right)$ had a conductivity of $3.4 \times 10^{2} \mathrm{~S} \mathrm{~cm}^{-1}$. In contrast, the PEDOT- and PA-based carbonaceous films prepared in the range of 600$1100{ }^{\circ} \mathrm{C}$ had conductivities on the order of $10^{-6}$ to $10^{0} \mathrm{~S} \mathrm{~cm}^{-1}$ and $10^{-3}$ to $10^{1} \mathrm{~S} \mathrm{~cm}^{-1}$, respectively (Fig. 6). The present PEDOT- and PA-based carbonaceous films have lower electrical conductivity than doped PEDOT film and PA film with doped iodine. This is an expected result because the carbonaceous films prepared at a relatively low temperature of $600-1100{ }^{\circ} \mathrm{C}$ still contain a large amount of $\mathrm{sp}^{3}$ carbon component, implying that the films are exist in an amorphous state. Such an amorphous and low-crystalline carbon material often shows relatively low electrical conductivity. The electrical conductivities of the carbonaceous films increased with increase in the heattreatment temperature. Note that the PEDOT and PA films 

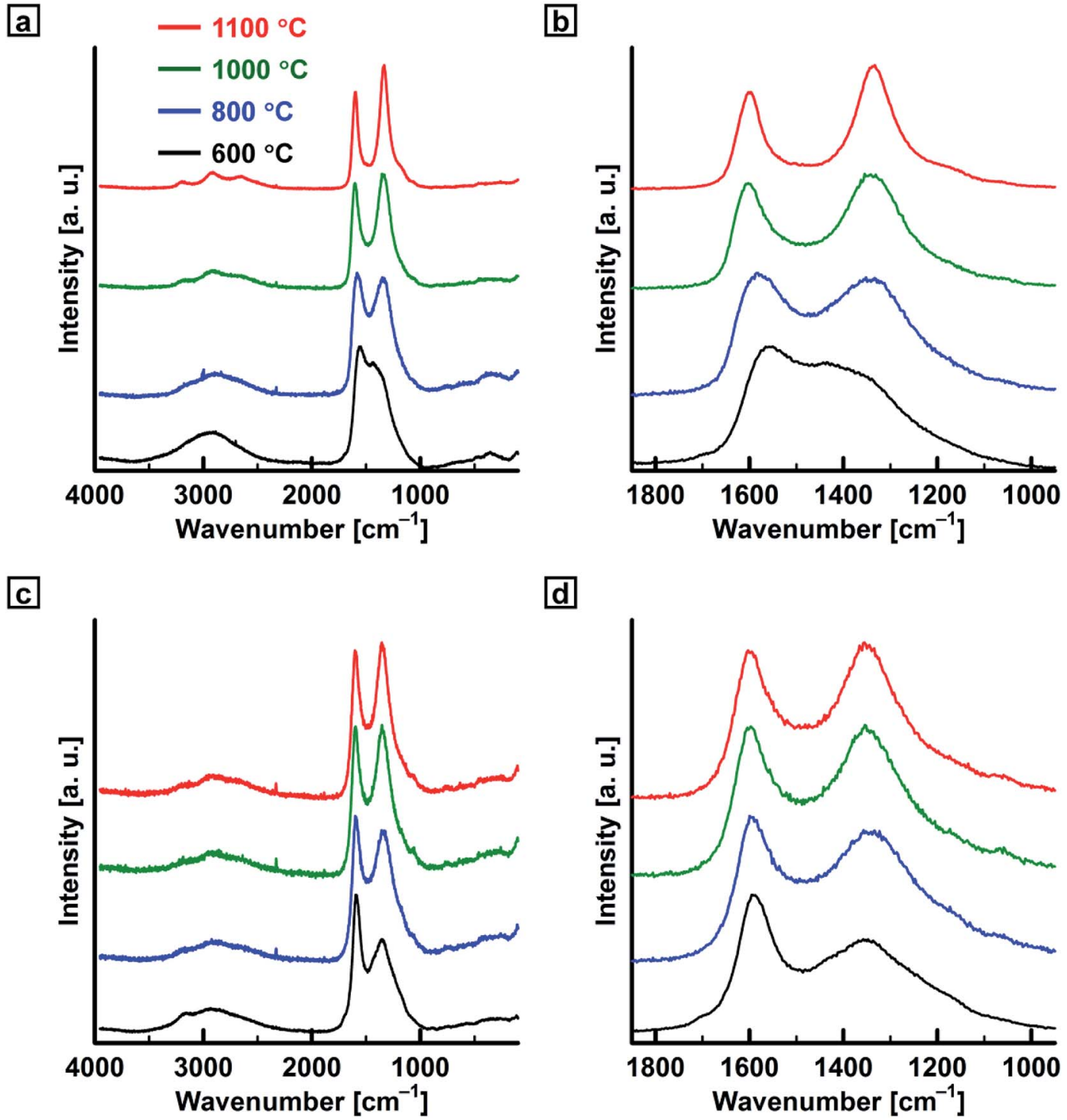

Fig. 5 Raman scattering spectra of the ( $a$ and b) PEDOT-based carbonaceous films and (c and d) PA-based carbon films prepared in the temperature range of $600-1100^{\circ} \mathrm{C}$.

carbonized at $1100{ }^{\circ} \mathrm{C}$ have approximately 5 orders and 4 orders of magnitude higher conductivities than those of the films carbonized at $600{ }^{\circ} \mathrm{C}$ do, respectively. The conductivity of the PA-based carbon film prepared at $1100{ }^{\circ} \mathrm{C}$ is approximately 48 times higher than that of the PEDOT-based carbonaceous film prepared at $1100{ }^{\circ} \mathrm{C}$. The large difference in electrical conductivity between the carbonaceous films was attributed to the difference in the $d_{\text {bulk }}$ values. The PA-based carbon film has a higher $d_{\text {bulk }}$ value in the range of $0.83-1.13 \mathrm{~g} \mathrm{~cm}^{-3}$ than that of the PEDOT-based carbonaceous film $\left(0.27-0.44 \mathrm{~g} \mathrm{~cm}^{-3}\right)$, leading to the high conductivity.

Table $2 S_{\mathrm{BET}}, S_{\text {micro, }} V_{\text {total }}, V_{\text {micro, }}$ and $D_{\text {average }}$ values for the PEDOT-based carbonaceous films and PA-based carbon films prepared in the temperature range of $1000-1100{ }^{\circ} \mathrm{C}$

\begin{tabular}{|c|c|c|c|c|c|c|c|c|}
\hline Polymer & $\begin{array}{l}\text { Heat-treatment } \\
\text { temp. }\left({ }^{\circ} \mathrm{C}\right)\end{array}$ & $S_{\mathrm{BET}}\left(\mathrm{m}^{2} \mathrm{~g}^{-1}\right)$ & $S_{\text {micro }}\left(\mathrm{m}^{2} \mathrm{~g}^{-1}\right)$ & $V_{\text {total }}\left(\mathrm{cm}^{3} \mathrm{~g}^{-1}\right)$ & $V_{\text {micro }}\left(\mathrm{cm}^{3} \mathrm{~g}^{-1}\right)$ & $S_{\text {micro }} / S_{\text {BET }}(\%)$ & $V_{\text {micro }} / V_{\text {total }}(\%)$ & $D_{\text {average }}(\mathrm{nm})$ \\
\hline PEDOT & 1000 & 715 & 689 & 0.3 & 0.26 & 96 & 85 & 1.7 \\
\hline \multirow[t]{2}{*}{$\mathrm{PA}$} & 1000 & 17.6 & 14.6 & 0.14 & $0.39 \times 10^{-2}$ & 83 & 2.8 & 31.9 \\
\hline & 1100 & 13.9 & 10.1 & 0.12 & $0.25 \times 10^{-2}$ & 73 & 2.1 & 33.7 \\
\hline
\end{tabular}




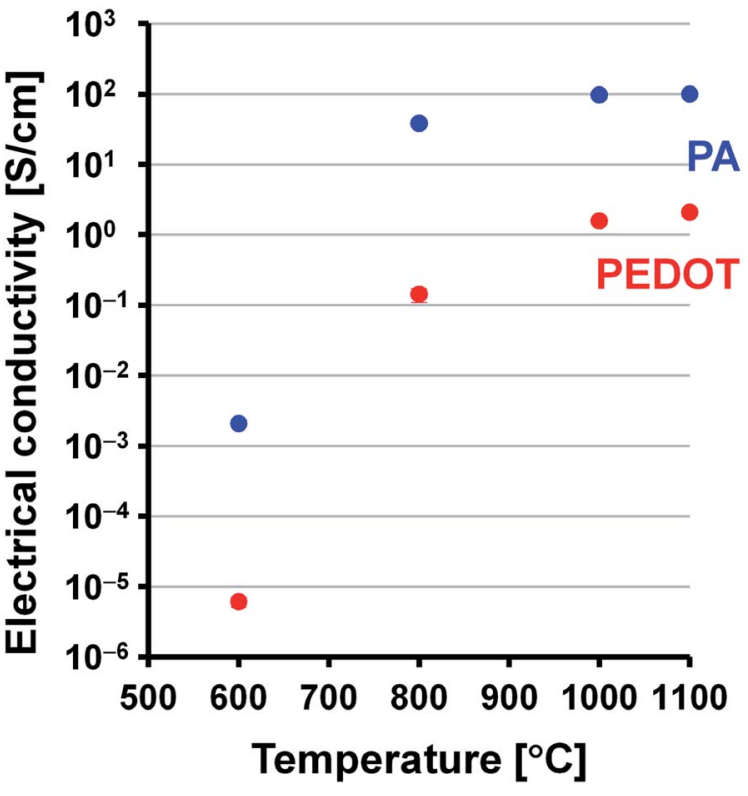

Fig. 6 Electrical conductivities of the PEDOT ( $t=64-144 \mu \mathrm{m})$ and PA $(t=66-76 \mu \mathrm{m})$ carbonaceous films as a function of the heat-treatment temperature. The error bars represent the standard deviation from several measurements.

\subsection{Cyclic voltammetry of PEDOT- and PA-based carbonaceous films}

Cyclic voltammetry was performed using a three-electrode system with $\mathrm{KCl}$ as the electrolyte at room temperature. A Pt wire, $\mathrm{Ag} / \mathrm{AgCl}$ electrode, and nickel plate were used as the counter electrode, reference, and current collector, respectively. In this work, we used the PEDOT- and PA-based carbonaceous films without any further treatment as electrode materials for the fabrication of working electrodes. The potential range and the scan rate were $-1.0-0.0 \mathrm{~V}$ or $-1.0-(-0.1) \mathrm{V}$ and $10-500 \mathrm{mV}$ $\mathrm{s}^{-1}$, respectively. No obvious sample damage was observed during the electrochemical experiments. Fig. 7, S23 and S25 (ESI $\dagger$ ) show cyclic voltammograms of the PEDOT- and PA-based carbonaceous films measured at various scan rates. The cyclic voltammograms of the PEDOT and PA films carbonized in the range of $1000-1100{ }^{\circ} \mathrm{C}$ showed typical capacitive behavior with no remarkable peaks and a quasi-rectangular shape profile. The cyclic voltammograms of the carbonaceous films remained rectangular-like shape with little distortion even at a high scan rate of $500 \mathrm{mV} \mathrm{s}^{-1}$, indicating good rate capability. On the other hand, the cyclic voltammograms of the carbonaceous film prepared in the range of $600-800{ }^{\circ} \mathrm{C}$ showed small rectangularlike waves independent of the scan rate, corresponding to low specific capacitances. This is mainly due to the relatively low carbon content and the low electrical conductivity of the film, resulting in the poor $\mathrm{CV}$ performance. The specific capacitances of the PEDOT-based carbonaceous and the PA-based carbon films decreased with an increase in the scan rate. The highest specific gravimetric capacitance $\left(C_{\mathrm{m}, \mathrm{CV}}\right)$ was recorded for the PEDOT-based carbonaceous film prepared at $1100{ }^{\circ} \mathrm{C}$. The maximum $C_{\mathrm{m}, \mathrm{CV}}$ values of the PEDOT-based carbonaceous films at scan rates of $10,20,50,100,200$, and $500 \mathrm{mV} \mathrm{s}^{-1}$ were calculated from the cyclic voltammograms to be $44,42,37,32$, 25 , and $17 \mathrm{~F} \mathrm{~g}^{-1}$, respectively. The maximum $C_{\mathrm{m}, \mathrm{Cv}}$ values of the PA-based carbon film at scan rates of 10, 20, 50, 100, 200, and $500 \mathrm{mV} \mathrm{s}^{-1}$ were calculated to be $7.8,7.7,7.5,7.1,6.7$, and $5.9 \mathrm{~F}$ $\mathrm{g}^{-1}$, respectively.

Although the PEDOT-based carbonaceous film has much lower electrical conductivity than the PA-based carbon film at the same heat-treatment temperature does, the former has a higher $C_{\mathrm{m}, \mathrm{Cv}}$ value than the latter. The unexpectedly low $C_{\mathrm{m}, \mathrm{Cv}}$ value of the PA-based carbon films is rationalized as follows: the main effect of the doped iodine in the PA film during the heat treatment is to prevent thermal decomposition of the film, as mentioned before. The decomposition reaction of the PA film is largely suppressed, as observed in the TG-DTA curve for the iodine-doped PA film (Fig. 2b). In other words, PA-based carbon films with relatively high electrical conductivities can be produced from the iodine-doped PA film. However, their $C_{\mathrm{m}, \mathrm{Cv}}$ values are quite low due to a lack of microporous structures and the existence of insufficient adsorption sites for electrolyte ions in the carbon film due to the large suppression of thermal decomposition during heat treatment. This lack of a microporous structure in the PA-based carbon film prepared in the range of $1000-1100{ }^{\circ} \mathrm{C}$ was confirmed by using BET measurements, as described previously (Table 2). Thus, low electrochemical performance was observed even for the PA-based carbon film prepared at the relatively high temperature of $1100{ }^{\circ} \mathrm{C}$. However, the PEDOT films carbonized above $1000{ }^{\circ} \mathrm{C}$ undergo clear thermal decomposition, which is believed to be indispensable for the formation of micropores, resulting in the relatively high $C_{\mathrm{m}, \mathrm{Cv}}$ value of the PEDOT-based carbonaceous films in contrast to that of the PA-based carbon films. A cyclability test was performed for the PEDOT-based carbonaceous film prepared at $1000^{\circ} \mathrm{C}$ with a relatively high $C_{\mathrm{m}, \mathrm{Cv}}$ value, and the cyclability test could be repeated 200 times using CV, demonstrating that the film had acceptable electrochemical stability (Fig. 7d). The shape of the cyclic voltammogram of the carbonaceous film scarcely changed, and the $C_{\mathrm{m}, \mathrm{CV}}$ value $\left[C_{\mathrm{m}, \mathrm{CV}}\right.$ $\left(200^{\text {th }}\right)=100 \%$ of $\left.C_{\mathrm{m}, \mathrm{CV}}\left(1^{\mathrm{st}}\right)\right]$ did not decrease even after 200 scans.

\subsection{Galvanostatic charge and discharge curves for the PEDOT- and PA-based carbonaceous films}

The GCD curves for PEDOT- and PA-based carbonaceous films were recorded at room temperature in the same potential range as that used in CV. The current density was varied from 0.1 to $5.0 \mathrm{~A} \mathrm{~g}^{-1}$. Fig. 8, S24 and S26 (ESI†) show GCD curves for the PEDOT- and PA-based carbonaceous films measured at various current densities. The PEDOT and PA films carbonized in the range of $1000-1100{ }^{\circ} \mathrm{C}$ showed more linear and triangular shape profiles than those for the films carbonized in the range of $600-$ $800{ }^{\circ} \mathrm{C}$, indicating ideal capacitive performance for the carbonaceous film. No significant IR drop was observed in the charge and discharge curves of the carbonaceous films even at a high current density of $5 \mathrm{~A} \mathrm{~g}^{-1}$, indicating that the films have good electrical conductivities (Fig. S27 in the ESI†). The specific capacitances of the PEDOT-based carbonaceous and the PA- 

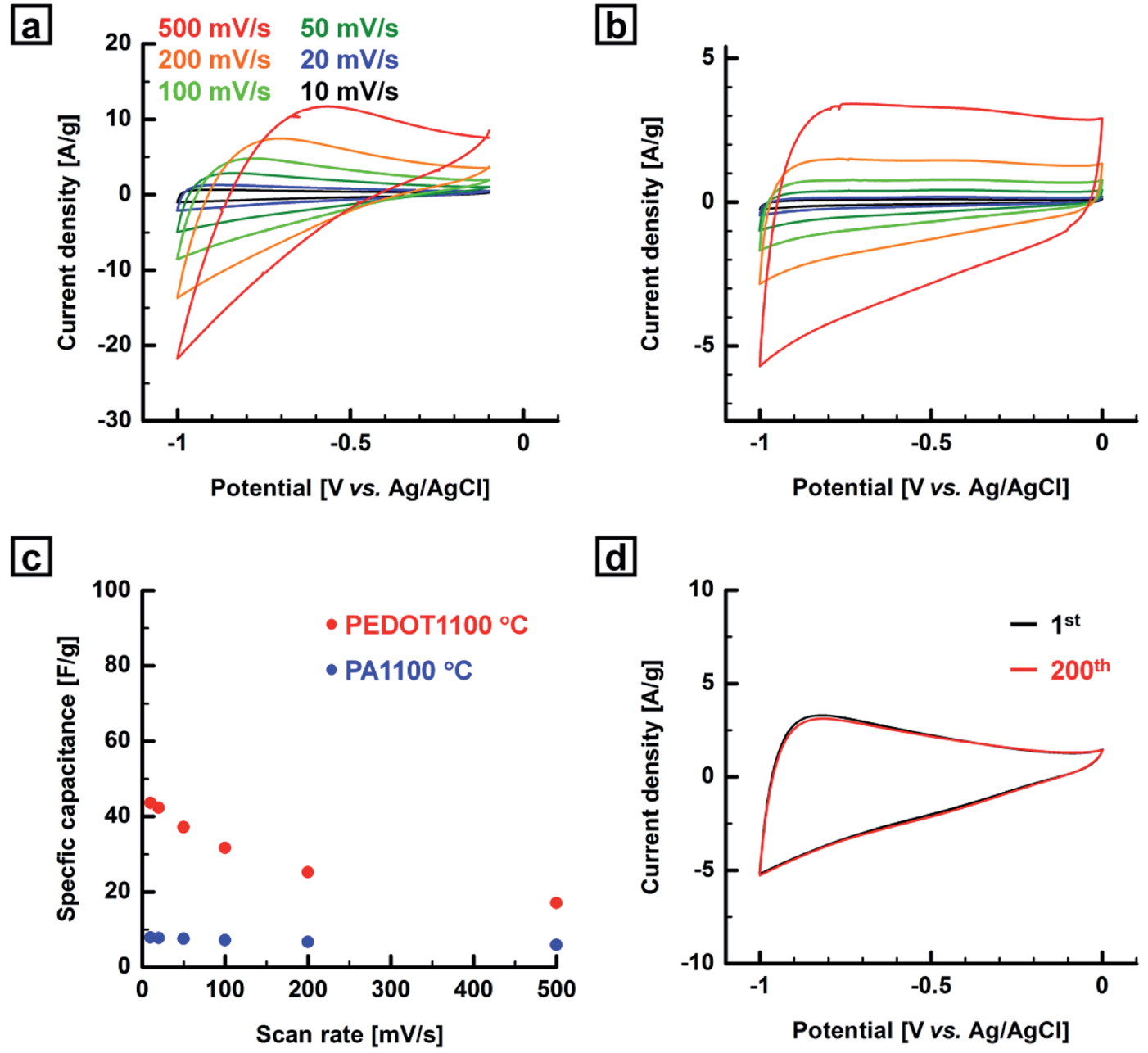

Fig. 7 Cyclic voltammograms of the (a) PEDOT- and (b) PA-based carbonaceous films prepared at $1100^{\circ} \mathrm{C}$ at various scan rates in $5 \mathrm{M} \mathrm{KCl}$ aq. (c) Relationship between specific capacitance and scan rate based on the cyclic voltammograms of the carbonaceous films prepared from the PEDOT and PA films. (d) Cyclic voltammograms of the PEDOT-based carbonaceous film prepared at $1000^{\circ} \mathrm{C}$ at a scan rate of $50 \mathrm{mV} \mathrm{s}{ }^{-1}$ in $5 \mathrm{M}^{\circ}$ $\mathrm{KCl}$ aq.

based carbon films decreased with an increase in the current density. The specific gravimetric capacitances $\left(C_{\mathrm{m}, \mathrm{GCD}}\right)$ of the carbonaceous films were calculated from the discharge curves in the potential range of $-1.0-0.0 \mathrm{~V}$. The PEDOT-based carbonaceous film prepared at $1000{ }^{\circ} \mathrm{C}$ was determined to have the highest $C_{\mathrm{m}, \mathrm{GCD}}$ value of $111 \mathrm{~F} \mathrm{~g}^{-1}$ with a low current density of $0.1 \mathrm{~A} \mathrm{~g}^{-1}$. When the current density was increased to $5 \mathrm{Ag}^{-1}$, the $C_{\mathrm{m}, \mathrm{GCD}}$ value remained at $56 \mathrm{~F} \mathrm{~g}^{-1}$, indicating a high-rate capacitive performance. In contrast, the maximum $C_{\mathrm{m}, \mathrm{GCD}}$ values of the PA-based carbon film at current densities of 0.1 , $0.2,0.5,1.0,2.0$, and $5.0 \mathrm{~A} \mathrm{~g}^{-1}$ were calculated to be $16,14,11$, 10,11 , and $16 \mathrm{~F} \mathrm{~g}^{-1}$, respectively. The PA-based carbon film showed a lower $C_{\mathrm{m}, \mathrm{GCD}}$ value than the PEDOT-based carbonaceous film did regardless of the heat-treatment temperature and current density. This agrees with the CV results. The $C_{\mathrm{m}}$ values of the carbonaceous films prepared from the PEDOT and PA films obtained from CV and GCD measurements as a function of heat-treatment temperature are summarized in Table S2 (ESI†).
Fig. 8d shows a Nyquist plot for the PEDOT-based carbonaceous film prepared at $1000{ }^{\circ} \mathrm{C}$. The equivalent series resistance (ESR) was estimated from the $x$-intercept of the Nyquist plot to be $1.4 \Omega$. The energy density of the PEDOT film carbonized at $1100{ }^{\circ} \mathrm{C}$ reached $14.0 \mathrm{~W} \mathrm{~h} \mathrm{~kg}^{-1}$ at a power density of $49.8 \mathrm{~W}$ $\mathrm{kg}^{-1}$. The relatively high energy density of the carbonaceous film was maintained at high power densities (Fig. S28 in the ESI $\dagger$ ). Finally, the PEDOT-based carbonaceous films prepared in the temperature range of $1000-1100{ }^{\circ} \mathrm{C}$ exhibited relatively high $C_{\mathrm{m}}$ values not only in a neutral aqueous electrolyte solution but also in an alkaline one. Fig. S29 (ESI†) shows electrochemical behaviors of the PEDOT-based carbonaceous film prepared at $1000^{\circ} \mathrm{C}$ measured by using $4 \mathrm{M} \mathrm{KOH}$ aq. as an electrolyte in the potential range from -1.0 to $-0.1 \mathrm{~V}(v s$. $\mathrm{Hg} / \mathrm{HgO})$. The $C_{\mathrm{m}}$ values of the carbonaceous film are summarized in Table S3 (ESI $\dagger$ ). The highest $C_{\mathrm{m}, \mathrm{GCD}}$ value was determined to be $69 \mathrm{~F} \mathrm{~g}^{-1}$ when the current density was $0.1 \mathrm{~A} \mathrm{~g}^{-1}$, demonstrating that the carbon material has reasonable capacitive properties even under an alkaline electrolyte conditions. 

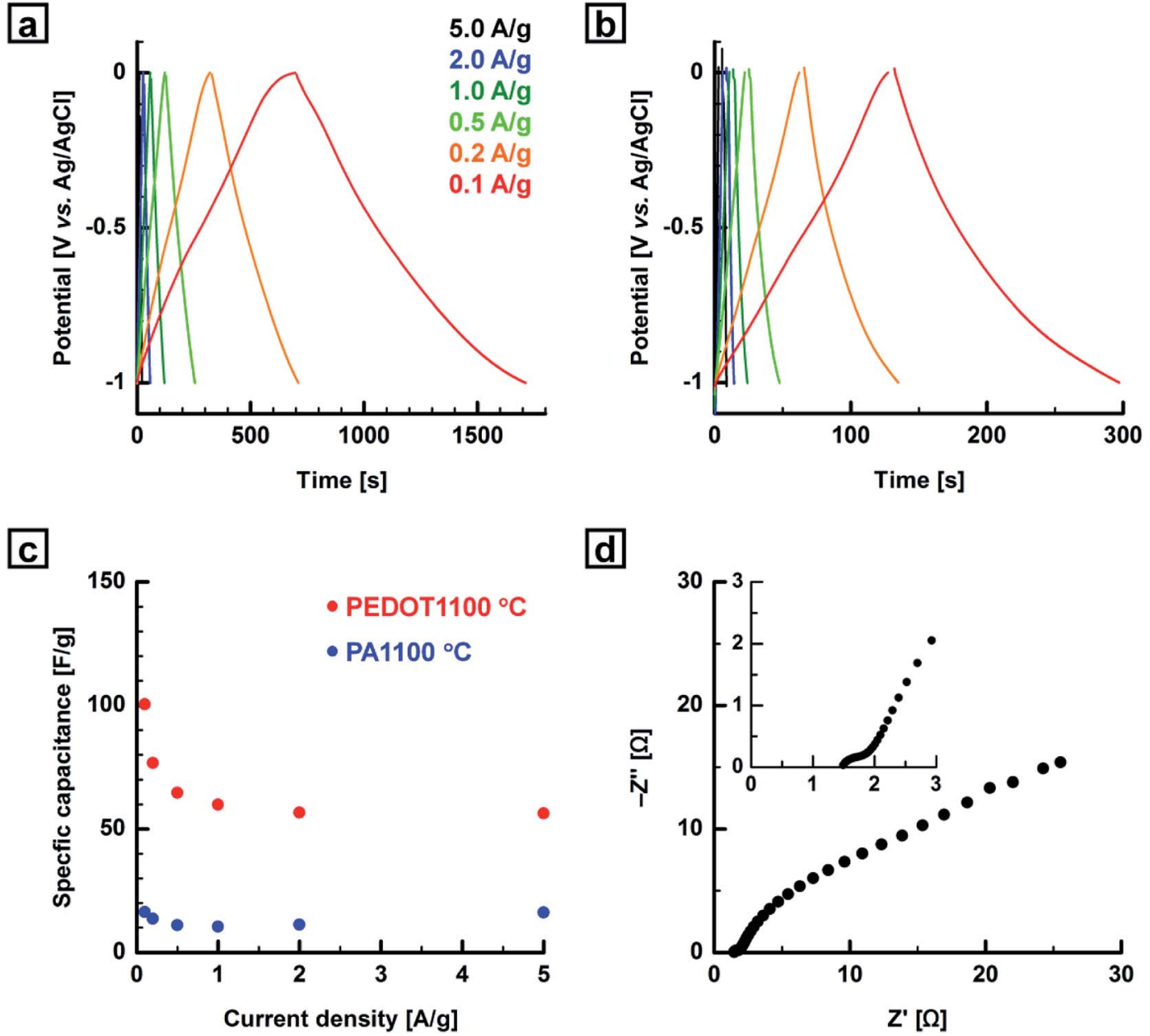

Fig. 8 GCD curves for the (a) PEDOT- and (b) PA-based carbonaceous films prepared at $1100{ }^{\circ} \mathrm{C}$ at various current densities in $5 \mathrm{M} \mathrm{KCl}$ aq. (c) Relationship between specific capacitance and current density based on the GCD curves of the carbonaceous films prepared from the PEDOT and PA films (potential range: $-1.0-0.0 \mathrm{~V}$ vs. Ag/AgCl). (d) Nyquist plot for the PEDOT-based carbonaceous film prepared at $1000{ }^{\circ} \mathrm{C}$ in $5 \mathrm{M} \mathrm{KCl}$ aq. The inset is a magnification of the plot.

It might be fruitful to summarize advanced points of the present PEDOT-based carbonaceous film. The carbonaceous film is more advanced than active carbon mixed with binders used in supercapacitor because they require no binders/ additives enabling one-step preparation without a timeconsuming film-making process and their direct use as carbon electrodes in supercapacitor. In addition, aging deterioration of supercapacitors caused by mixing with binders can be effectively suppressed. On the other hand, the carbonaceous film is more advanced than other free-standing carbon-based films used in supercapacitor because they can be easily prepared via morphology-retaining carbonization of doped PEDOT films as precursors and require no further activation processes or additional treatments for the enhancement of the capacities. The carbonization precursor films can also be directly synthesized by using a very simple electrochemical polymerization procedure with a short reaction time of $1 \mathrm{~h}$. Moreover, we have recently developed to produce carbonaceous and graphitic materials with hierarchical helical morphologies or highly aligned structures from electrochemically synthesized or solid-state polymerized PEDOT materials. ${ }^{13,20}$ We believe that the capacities are expected to be more enhanced than the present carbonaceous films by using the morphology-controlled carbon materials as supercapacitor electrodes owing to their ordered structures. This morphological controllability for the PEDOT-based carbon materials is also a superior point for the development of advanced supercapacitor electrodes.

\section{Conclusions}

It was demonstrated that carbonaceous films prepared from acceptor-doped conjugated polymer films in the range 1000$1100{ }^{\circ} \mathrm{C}$ showed good performances as supercapacitor electrodes on the basis of their high electrical conductivities and hierarchical porous morphologies. The electrochemical performance of the carbonaceous film electrodes largely depended on the heating temperature. In particular, the PEDOT film carbonized at $1000^{\circ} \mathrm{C}$ exhibited the highest $C_{\mathrm{m}, \mathrm{GCD}}$ value of 111 $\mathrm{F} \mathrm{g}^{-1}$ at a low current density of $0.1 \mathrm{~A} \mathrm{~g}^{-1}$ determined by using GCD measurements in neutral aqueous solutions. The value is comparable to $C_{\mathrm{m}}$ values reported for cellulose-derived 2D carbon materials.. ${ }^{11 b, c, e, i}$ To the best of our knowledge, this is the 
first report of PEDOT- and PA-based carbonaceous films being used as carbon electrodes for energy-storage devices. The present carbonaceous films require no binders/additives and no further activation processes or additional treatments for the enhancement of the capacities, enabling one-step preparation and their direct use as carbon electrodes in supercapacitors. The capacitive properties of the present carbonaceous films can be enhanced further by using a chemical or physical activation process. $^{27}$ Moreover, the present conjugated polymer-based carbonaceous films will expand the morphological variety of supercapacitor electrode materials and could be readily used for practical applications. Finally, since conjugated polymer films synthesized through liquid crystal polymerization methods afford carbonaceous films with anisotropic structures or hierarchical helical morphologies via a morphology-retaining carbonization method, ${ }^{28}$ electrochemical investigations of the morphologically controlled carbonaceous films as advanced supercapacitor electrodes are necessary. In addition, to investigate the specific impact of the amount and type of heteroatoms on the morphology and electrochemical performance is also the main scope of the future study.

\section{Conflicts of interest}

There are no conflicts to declare.

\section{Acknowledgements}

We would like to thank Dr T. Takei (NIMS, Japan) for the TEM measurements and NIMS Battery Research Platform for the BET measurements. This work was supported by a Grant-in-Aid for Scientific Research (A) (No. 13370214) and that for Young Scientists (A) (No. 16H06051) from the Ministry of Education, Culture, Sports, Science and Technology, Japan. This work was partially supported by the MEXT Program for Development of Environmental Technology using Nanotechnology.

\section{References}

1 (a) P. Simon and Y. Gogotsi, Nat. Mater., 2008, 7, 845-854; (b) P. Simon and Y. Gogotsi, Acc. Chem. Res., 2013, 46, 10941103; (c) M. R. Lukatskaya, B. Dunn and Y. Gogotsi, Nat. Commun., 2016, 7, 12647.

2 C. Liu, F. Li, L.-P. Ma and H.-M. Cheng, Adv. Mater., 2010, 22, E28-E62.

3 Y. Zhu, S. Murali, M. D. Stoller, K. J. Ganesh, W. Cai, P. J. Ferreira, A. Pirkle, R. M. Wallace, K. A. Cychosz, M. Thommes, D. Su, E. A. Stach and R. S. Ruoff, Science, 2011, 332, 1537-1541.

4 Y. Zhai, Y. Dou, D. Zhao, P. F. Fulvio, R. T. Mayes and S. Dai, Adv. Mater., 2011, 23, 4828-4850.

5 H. Jiang, P. S. Lee and C. Li, Energy Environ. Sci., 2013, 6, 4153.

6 X. Lu, M. Yu, G. Wang, Y. Tong and Y. Li, Energy Environ. Sci., 2014, 7, 2160-2181.

7 P. Pachfule, D. Shinde, M. Majumder and Q. Xu, Nat. Chem., 2016, 8, 718-724.
8 (a) Z. Zhang, Z. Huang, L. Ren, Y. Shen, X. Qi and J. Zhong, Electrochim. Acta, 2014, 149, 316-323; (b) Z. Huang, Z. Zhang, X. Qi, X. Ren, G. Xu, P. Wan, X. Sun and H. Zhang, Nanoscale, 2016, 8, 13273-13279; (c) X. Liu, X. Qi, Z. Zhang, L. Ren, G. Hao, Y. Liu, Y. Wang, K. Huang, X. Wei, J. Li, Z. Huang and J. Zhong, RSC Adv., 2014, 4, 13673-13679; (d) X. Chen, G. Xu, X. Ren, Z. Li, X. Qi, K. Huang, H. Zhang, Z. Huang and J. Zhong, J. Mater. Chem. A, 2017, 5, 6581-6588.

9 (a) V. L. Pushparaj, M. M. Shaijumon, A. Kumar, S. Murugesan, L. Ci, R. Vajtai, R. J. Linhardt, O. Nalamasu and P. M. Ajayan, Proc. Natl. Acad. Sci. U. S. A., 2007, 104, 13574-13577; (b) L. Hu, J. W. Choi, Y. Yang, S. Jeong, F. L. Mantia, L.-F. Cui and Y. Cui, Proc. Natl. Acad. Sci. U. S. A., 2009, 106, 21490-21494; (c) A. Izadi-Najafabadi, S. Yasuda, K. Kobashi, T. Yamada, D. N. Futaba, H. Hatori, M. Yumura, S. Iijima and K. Hata, Adv. Mater., 2010, 22, E235-E241; (d) Z. Niu, W. Zhou, J. Chen, G. Feng, H. Li, W. Ma, J. Li, H. Dong, Y. Ren, D. Zhao and S. Xie, Energy Environ. Sci., 2011, 4, 1440-1446.

10 (a) X. Lu, H. Dou, B. Gao, C. Yuan, S. Yang, L. Hao, L. Shen and X. Zhang, Electrochim. Acta, 2011, 56, 5115-5121; (b) X. Yang, J. Zhu, L. Qiu and D. Li, Adv. Mater., 2011, 23, 2833-2838; (c) H. Gwon, H.-S. Kim, K. U. Lee, D.-H. Seo, Y. C. Park, Y.-S. Lee, B. T. Ahn and K. Kang, Energy Environ. Sci., 2011, 4, 1277-1283; (d) Z. Weng, Y. Su, D. W. Wang, F. Li, J. Du and H.-M. Cheng, Adv. Energy Mater., 2011, 1, 917-922; (e) H. Gao, F. Xiao, C. B. Ching and H. Duan, ACS Appl. Mater. Interfaces, 2012, 4, 70207026; (f) Z.-S. Wu, A. Winter, L. Chen, Y. Sun, A. Turchanin, X. Feng and K. Müllen, Adv. Mater., 2012, 24, 5130-5135; $(g)$ F. Liu, S. Song, D. Xue and H. Zhang, Adv. Mater., 2012, 24, 1089-1094; (h) X. Yang, C. Cheng, Y. Wang, L. Qiu and D. Li, Science, 2013, 341, 534-537; (i) H.-P. Cong, X.-C. Ren, P. Wang and S.-H. Yu, Energy Environ. Sci., 2013, 6, 1185-1191; (j) Y. He, W. Chen, X. Li, Z. Zhang, J. Fu, C. Zhao and E. Xie, ACS Nano, 2013, 7, 174-182; (k) Z. Xiong, C. Liao, W. Han and X. Wang, Adv. Mater., 2015, 27, 4469-4475; (l) L. J. Wang, M. F. El-Kady, S. Dubin, J. Y. Hwang, Y. Shao, K. Marsh, B. McVerry, M. D. Kowal, M. F. Mousavi and R. B. Kaner, Adv. Energy Mater., 2015, 5, 1500786; ( $m$ ) W. Quan, Z. L. Tang, S. T. Wang, Y. Hong and Z. T. Zhang, Chem. Commun., 2016, 52, 3694-3696; (n) Y. Shao, M. F. El-Kady, C.-W. Lin, G. Zhu, K. L. Marsh, J. Y. Hwang, Q. Zhang, Y. Li, H. Wang and R. B. Kaner, Adv. Mater., 2016, 28, 6719-6726; (o) H. Nishihara, T. Simura, S. Kobayashi, K. Nomura, R. Berenguer, M. Ito, M. Uchimura, H. Iden, K. Arihara, A. Ohma, Y. Hayasaka and T. Kyotani, Adv. Funct. Mater., 2016, 26, 6418-6427.

11 (a) K. Babel and K. Jurewicz, J. Phys. Chem. Solids, 2004, 65, 275-280; (b) K. E. Shopsowitz, W. Y. Hamad and M. J. MacLachlan, Angew. Chem., Int. Ed., 2011, 50, 1099110995; (c) L. Bao and X. Li, Adv. Mater., 2012, 24, 32463252; (d) K. Gao, Z. Shao, J. Li, X. Wang, X. Peng, W. Wang and F. Wang, J. Mater. Chem. A, 2013, 1, 63-67; (e) L. Jiang, G. W. Nelson, H. Kim, I. N. Sim, S. O. Han and J. S. Foord, ChemistryOpen, 2015, 4, 586-589; $(f)$ Y. Li, J. Dong, 
J. Zhang, X. Zhao, P. Yu, L. Jin and Q. Zhang, Small, 2015, 11, 3476-3484; (g) K. Qin, J. Kang, J. Li, C. Shi, Y. Li, Z. Qiao and N. Zhao, ACS Nano, 2015, 9, 481-487; (h) X. Zhou, Q. Chen, A. Wang, J. Xu, S. Wu and J. Shen, ACS Appl. Mater. Interfaces, 2016, 8, 3776-3783; ( $i$ ) L. Jiang, G. W. Nelson, S. O. Han, H. Kim, I. N. Sim and J. S. Foord, Electrochim. Acta, 2016, 192, 251-258.

12 D. Zhu, Y. Liu, L. Yuan, Y. Liu, X. Li, L. Yi, H. Wei and K. Yao, RSC Adv., 2014, 4, 63734-63740.

13 (a) S. Matsushita, B. Yan, S. Yamamoto, Y. S. Jeong and K. Akagi, Angew. Chem., Int. Ed., 2014, 53, 1659-1663; (b) B. Yan, S. Matsushita and K. Akagi, Chem. Mater., 2016, 28, 8781-8791.

14 M. Kyotani, S. Matsushita, T. Nagai, Y. Matsui, M. Shimomura, A. Kaito and K. Akagi, J. Am. Chem. Soc., 2008, 130, 10880-10881.

15 S. Matsushita, M. Kyotani and K. Akagi, J. Am. Chem. Soc., 2011, 133, 17977-17992.

16 S. Matsushita and K. Akagi, J. Am. Chem. Soc., 2015, 137, 9077-9087.

17 M. Goh, S. Matsushita and K. Akagi, Chem. Soc. Rev., 2010, 39, 2466-2476.

18 B. Yan, S. Matsushita, K. Suda and K. Akagi, Chem. Mater., 2015, 27, 2973-2980.

19 (a) L. Pan, G. Yu, D. Zhai, H. R. Lee, W. Zhao, N. Liu, H. Wang, B. C.-K. Tee, Y. Shi, Y. Cui and Z. Bao, Proc. Natl. Acad. Sci. U. S. A., 2012, 109, 9287-9292; (b) J. W. F. To, Z. Chen, H. Yao, J. He, K. Kim, H.-H. Chou, L. Pan, J. Wilcox, Y. Cui and Z. Bao, ACS Cent. Sci., 2015, 1, 68-76.

20 B. Yan, S. Matsushita and K. Akagi, J. Mater. Chem. C, 2017, 5, 3823-3829.

21 (a) Y. Kou, Y. Xu, Z. Guo and D. Jiang, Angew. Chem., Int. Ed., 2011, 50, 8753-8757; (b) X. Zhuang, F. Zhang, D. Wu, N. Forler, H. Liang, M. Wagner, D. Gehrig, M. R. Hansen, F. Laquai and X. Feng, Angew. Chem., Int. Ed., 2013, 52,
9668-9672; (c) J.-S. M. Lee, T.-H. Wu, B. M. Alston, M. E. Briggs, T. Hasell, C.-C. Hu and A. I. Cooper, J. Mater. Chem. A, 2016, 4, 7665-7673.

22 X. Feng, Y. Liang, L. Zhi, A. Thomas, D. Wu, I. Lieberwirth, U. Kolb and K. Müllen, Adv. Funct. Mater., 2009, 19, 21252129.

23 Z. Xiang, D. Wang, Y. Xue, L. Dai, J.-F. Chen and D. Cao, Sci. Rep., 2015, 5, 8307.

24 (a) R. Kiebooms, A. Aleshin, K. Hutchison and F. Wudl, J. Phys. Chem. B, 1997, 101, 11037-11039; (b) Y. Lei, H. Oohata, S. Kuroda, S. Sasaki and T. Yamamoto, Synth. Met., 2005, 149, 211-217.

25 (a) G. Hasegawa, M. Aoki, K. Kanamori, K. Nakanishi, T. Hanada and K. Tadanaga, J. Mater. Chem., 2011, 21, 2060-2063; (b) X. Zhao, Q. Zhang, C.-M. Chen, B. Zhang, S. Reiche, A. Wang, T. Zhang, R. Schlögl and D. S. Su, Nano Energy, 2012, 1, 624-630; (c) M. Seredych and T. J. Bandosz, J. Mater. Chem. A, 2013, 1, 11717-11727; (d) J. P. Paraknowitsch and A. Thomas, Energy Environ. Sci., 2013, 6, 2839-2855; (e) X. Ma, G. Ning, Y. Kan, Y. Ma, C. Qi, B. Chen, Y. Li, X. Lan and J. Gao, Electrochim. Acta, 2014, 150, 108-113; $(f)$ M. Seredych, K. Singh and T. J. Bandosz, Electroanalysis, 2014, 26, 109-120; $(g)$ W. Kiciński, M. Szala and M. Bystrzejewski, Carbon, 2014, 68, 1-32; (h) K. Singh, M. Seredych, E. R. Castellon and T. J. Bandosz, ChemElectroChem, 2014, 1, 565-572; (i) N. Parveen, M. O. Ansari, S. A. Ansari and M. H. Cho, J. Mater. Chem. A, 2016, 4, 233-240.

26 M. Kyotani, S. Matsushita, M. Goh, T. Nagai, Y. Matsui and K. Akagi, Nanoscale, 2010, 2, 509-514.

27 J. Wang and S. Kaskel, J. Mater. Chem., 2012, 22, 2371023725.

28 S. Matsushita, B. Yan and K. Akagi, Synth. Met., 2016, 216, 103-112. 